\title{
PROGRAMAS E PRÁTICAS PEDAGÓGICAS NA EDUCAÇÃO ESPECIAL E INCLUSIVA
}

\author{
Carla Luciane Blum Vestena \\ Carla Maria de Schipper \\ Flávia Faissal de Soura
}

A seção temática deste número reúne uma coletânea de 17 textos de pesquisadores de diversos estados brasileiros e um de pesquisadores de Cuba e do Equador que evidenciam a problemática das práticas pedagógicas no contexto da educação especial na perspectiva das políticas de educação inclusiva. Para além dos diferentes contextos históricos, políticos e sociais, e distintas abordagens teórico-metodológicas, os textos que compõem a seção de Teias apresentam como foco central o processo de escolarização de alunos com deficiências, transtornos globais do desenvolvimento e altas habilidades/superdotação, trazendo questões do campo da educação especial na relação com: a organização e a estrutura política de programas educacionais; as relações de ensino na educação básica e na modalidade da educação de jovens e adultos; as especificidades dos processos de ensino e aprendizagem; propostas de formação de professores com análise de experiência em universidade e em formação continuada.

As políticas de educação especial, pautadas em princípios das políticas de educação inclusiva, passaram a configurar o cenário educacional brasileiro nas diferentes esferas administrativas, há cerca de 25 anos. Contudo, os discursos sobre a construção de uma educação pautada em diferenças e singularidades humanas foram ampliados com a construção de políticas e programas federais no início dos anos 2000. Nesse cenário, as escolas vêm se (re)construindo em meio a muitos tensionamentos, entre normas que preveem a construção de escolas inclusivas; as políticas de educação básica de caráter meritocrático; o estatuto histórico da função social da escola e da pessoa com deficiência; e o financiamento dos programas que compõem as ações políticas no âmbito da educação especial, entre outros.

Com a Política Nacional de Educação Especial na Perspectiva da Educação Inclusiva (BRASIL, 2008) temos um denso conjunto de documentos legislativos que regulam os princípios que normatizam a escolarização dos alunos da educação especial no ensino comum, pautando a urgência da construção do trabalho pedagógico adequado para atender suas singularidades na coletividade. Para tal, dois eixos políticos são centrais: a formação inicial e continuada de professores e a instituição do serviço do Atendimento Educacional Especializado (AEE).

O AEE é um serviço de educação complementar e/ou suplementar, oferecido no contraturno aos alunos com deficiência, altas habilidades/superdotação e transtornos globais do desenvolvimento, matriculados em classes comuns do ensino regular. Por esse serviço, deve ser ofertado ao aluno um conjunto de atividades, recursos de acessibilidade e pedagógicos organizados institucional e continuamente, mas pautados em atividades que "[...] diferenciam-se daquelas realizadas na sala de aula comum, não sendo substitutivas à escolarização" (BRASIL, 2008, p. 10). Com base em ideias mais amplas de acessibilidade e no modelo social de deficiência — cujo argumento central é que as barreiras sociais, culturais e históricas que impactam a plena participação social e o desenvolvimento da pessoa com deficiência devem ser removidas -, o AEE é um apoio especializado que deve eliminar as barreiras de acesso ao conhecimento que possam obstruir o processo de escolarização do alunado da educação especial. 
Nos documentos normativos é prevista a articulação entre o professor da sala de aula comum e do AEE para a construção da proposta de escolarização dos alunos com deficiência, altas habilidades/superdotação e transtornos globais do desenvolvimento. Contudo, já foram bastante relatadas tanto as parcas iniciativas de formação dos professores não especialistas como, também, a falta de condições, em muitos municípios brasileiros, para o desenvolvimento do trabalho pedagógico conjunto.

Ainda, a formação de professores para atuar no contexto das políticas de educação inclusiva é posta como um grande desafio, tanto pelas adversidades das condições de trabalho como pela necessidade de ressignificação de múltiplas dimensões que compõem o trabalho pedagógico. Não distante, o trabalho docente é um ponto fulcral na construção de redes de ensino e de escolas inclusivas. Para além do professor especialista do AEE, há a necessidade de formação do professor do ensino comum. Diferentes documentos políticos nacionais e internacionais apontam para a necessidade de formação docente que possibilite ressignificação das concepções de deficiência marcadas pelo viés médico e a construção de conhecimentos, a fim de dar suporte à elaboração de currículos e estratégias apropriadas para que cada aluno possa aprender, a partir de um amplo repertório de metodologias, estratégias de mediação pedagógica e de avaliação que construam possibilidades de inserção de todos os alunos nos processo de ensino e aprendizagem (SOUZA, PLETSCH, 2017).

A proposta política de todos os alunos aprenderem juntos e sem discriminação, da educação básica ao ensino superior, mesmo que sob um viés liberal, traz a igualdade e equidade como princípio e a diferença como direito. A partir dessa concepção, a organização das escolas, sua estrutura curricular, física e de pessoal passa por uma reorganização para atender as especificidades de todos os alunos. A ideia é que o aluno aprenda sentindo-se valorizado e que sejam observadas suas necessidades e suas aptidões, potencializadas. Isso é possível em programas e práticas pedagógicas que se estruturem em atividades centradas na relação do aluno, de seus pares, do professor e do conhecimento.

Experiências educacionais bem planejadas têm mais chance de obter sucesso no processo de escolarização, portanto, exigem que o professor também respeite as subjetividades dos alunos. Para tal, os conteúdos precisam ser significativos, de forma a não frear a construção do pensamento e da criatividade e, principalmente, evitar a mera reprodução de conteúdos, pois “[...] não se trata simplesmente de repassá-los mecanicamente aos alunos, uma vez que o papel social da escola é permitir a apropriação crítica, criativa, significativa e duradoura do conteúdo" (NADAL et al, 2007 p. 18).

Entre as diferentes propostas, muitas discussões atuais sobre a prática pedagógica no contexto das políticas de educação inclusiva trazem o Design Universal de Aprendizagem (DUA), um conceito assentado nos princípios de acessibilidade e funcionalidade a todos os estudantes, que "[...] vem somar à área da Educação Especial, uma vez que visualiza os indivíduos de maneira única e se propõe a pensar nas suas peculiaridades" (OLIVEIRA, VAN MUNSTER, GONÇALVES, 2019, p. 676). Este modelo se impôs diante de práticas que se propunham inclusivas, e promoviam a flexibilização curricular de modo a esvaziar o conteúdo, não garantindo a "[...] apropriação do conhecimento historicamente acumulado pela humanidade e legitimado nas estruturas curriculares da educação formal em seus diferentes níveis de ensino" (SILVA, BEGO, 2018, p. 345).

Portanto, para que se proporcionem oportunidades de aprendizagem almejadas para todos os estudantes, as práticas pedagógicas inclusivas são aquelas que se valem de estratégias metodológicas que assegurem todas as oportunidades de aprendizagem de conteúdos curriculares e ampliação do saber pelos alunos com deficiência e transtornos globais do desenvolvimento, assim como o enriquecimento curricular para alunos com altas habilidades/superdotação, sem 
desconsiderar o trabalho emocional para minimizar consequências psicológicas, fruto da padronização das metodologias de ensino e avaliação.

Ao propormos esta seção temática que versa sobre programas e práticas pedagógicas na educação especial inclusiva, em todas as áreas, compreendemos que estaríamos contribuindo para preencher uma lacuna de pesquisa.

Para justificar essa pretensão nos valemos, por exemplo, dos estudos de Pletsch (2014) que, ao analisar a escolarização de pessoas com deficiência intelectual entre os anos de 1973 a 2013, destaca que é preciso modificações na escolarização dos alunos com deficiência intelectual, afirmando a necessidade de ampliar pesquisas que avaliem processos de ensino e aprendizagem desses alunos, estratégias curriculares e recursos por eles utilizados. A proposta é adensada ao observarmos outros estudos na área como de Coelho e Sodré (2019); Cechin, Costa e Dorneles (2013); Braun e Nunes (2015); Brito, Campos e Romanatto (2014); Rossit e Goyos (2015); Mori et al (2017); Escobal, Rossit e Goyos (2010); Miranda e Pinheiro (2016); Silva e Sani et al. (2017); Seibert e Groenwald (2014) e Viginheski (2017) que, após análise de distintas formas de intervenções, tratam da potencialidade da aprendizagem e do desenvolvimento dos alunos com deficiência intelectual.

Contudo, analisando as vicissitudes do conceito social de deficiência e das práticas da educação especial, observa-se ainda um alto grau de dependência do aluno às decisões dos adultos ou das instituições escolares, obra da superproteção e da hegemonia adulta sobre sua existência assentada, como descreve Glat (2018, p. 9), em concepções sociais de fragilidade do modelo médico-assistencialista para o de dificuldade do modelo educacional, até chegar ao modelo para o desenvolvimento, autonomia, competência e inclusão que a autora denomina como "[...] modelo psicossocial e de auto-gestão".

No terreno da educação sob os princípios das políticas de educação inclusiva, os artigos presentes, neste número de Teias, contribuirão para o fortalecimento de modelos explicativos da deficiência, pautados no campo dos Direitos Humanos e na negação de modelos pautados no determinismo biológico, deslocando-o para o conceito de deficiência como produto do meio e socialmente construído (OMOTE, 2018); quanto aos alunos com altas habilidades/superdotação, desmitificam-se falsas crenças construídas acerca de suas peculiaridades cognitivas e emocionais.

Alguns mitos sobre pessoas com altas habilidades/superdotação construídos historicamente, e de modo equivocado, interferem na forma como muitas pessoas os compreendem como, por exemplo, a ideia de que a pessoa é autodidata, é gênio, sabe tudo, é geneticamente privilegiada, domina todas as áreas do conhecimento e de que não necessita de atendimento educacional especializado ou apoio emocional, pois tudo é fácil para ela (PÉREZ, 2003).

Ao promover a desconstrução de estereótipos haverá contribuições para reflexões pautadas na diferença como constitutiva do humano, a fim de aprofundar o debate sobre os princípios da educação inclusiva no âmbito conceitual. No aspecto das práticas pedagógicas, a divulgação de procedimentos bem-sucedidos no ensino também tem o papel de revigorar processos educacionais inclusivos, já que trazem possibilidades de aprendizagem e de desenvolvimento, quando há sistematização, sentido e intencionalidade. Contudo, os textos apresentados vão além de meras técnicas pedagógicas, pois os autores compreendem que "[...] nas práticas pedagogicamente construídas, há a mediação do humano e não a submissão do humano a um artefato técnico previamente construído" (FRANCO, 2016, p. 535-536).

Ao divulgarmos concepções e práticas pedagógicas em um posicionamento "humano", contribuiremos para o fortalecimento dos princípios da inclusão, pois a Política Nacional de Inclusão de 2008 encontra-se ameaçada, já que o MEC vem sinalizando revisão dessa política, 
abrindo precedentes para a volta da concepção médica da deficiência, como balizadora de propostas educacionais segregacionistas. Ao retomar perspectivas já superadas, caminha-se na contramão da compreensão socioantropológica e de direitos sociais duramente conquistados.

No terreno da educação especial institucionalizada, a seção temática colaborará para a desmitificação da ideia de incapacidade e determinismo biológico da deficiência, como observado por Rossato e Leonardo (2011); Leonel e Leonardo (2014); dos Santos, Mendonça e Oliveira (2014); e Vargas e Portilho (2018). Os(as) autores(as) citados(as), em estudos sobre concepções de professores quanto à educação especial na área da deficiência intelectual e de transtornos globais do desenvolvimento, detectaram limitações na compreensão da deficiência, minimizando a aprendizagem, atribuindo dificuldades aos alunos e a suas características, reforçando a ausência de habilidades em uma "[...] naturalização do não aprender, numa concepção de incapacidade para o aprendizado dos conhecimentos científicos, centradas numa irreversibilidade orgânica" (ROSSATO, LEONARDO, 2011, p. 71).

Pimenta e Anastasiou (2002) destacam que um dos fundamentos científicos da história da didática é a psicologia a-histórica e naturalizante, a qual coloca o ser humano como o único responsável pelo seu fracasso. Essa forma de refletir a didática acaba, do mesmo modo, por acerar técnicas, procedimentos e métodos de ensinar.

Para Zabala (1998), a prática pedagógica é baseada no pensamento experimentado, mas com capacidade reflexiva para analisar as variáveis que configuram as práticas, que são parâmetros institucionais e organizativos; as tradições metodológicas; as possibilidades reais dos professores; as condições do meio e as condições físicas existentes.

"A atividade teórica por si só não leva à transformação da realidade; não se objetiva e não se materializa, não sendo, pois, práxis". Por outro lado, “[...] a prática também não fala por si mesma, quer dizer, teoria e prática são indissociáveis como práxis” (PIMENTA, GHEDIN, 2005, p. 38). De tal modo, os domínios da relação entre o que é denominado de teoria e prática se entretecem em diferentes momentos da formação profissional e ao longo da carreira docente. É por meio do processo de reflexão-ação-reflexão que se estrutura a práxis docente. Por isso, a formação de professores deve se dar de modo processual, isto é, antes e durante o percurso profissional do professor, por suas diversas vivências, em perspectiva histórico-cultural. A partir desse princípio, tal formação necessita tanto de estrutura conceitual como de amplo repertório de estratégias de mediação, ao buscar a percepção de como estas serão desenvolvidas no cotidiano escolar.

No contexto inclusivo, no que se refere aos parâmetros legais e organizacionais há uma forte sustentação, mas as fragilidades provêm das práticas que ainda se sustentam em tradições metodológicas homogeneizantes e meritocráticas. Outra vulnerabilidade se refere às condições materiais e de formação ofertadas aos professores no espaço inclusivo. Serão nocivas às propostas de redes educacionais e escolas inclusivas as tradições metodológicas que enfatizam a deficiência, pois podem gerar ações educativas pouco estimuladoras (SANTOS, MENDONÇA, OLIVEIRA, 2014, p. 45).

Caniato (1992) destaca que o processo de aquisição de conhecimento deve envolver a brincadeira de descobrir e fazer, ensinar usando as mãos, ou seja, experimentando; considerar os saberes prévios dos estudantes; inserir os conhecimentos na realidade do aluno; problematizar os conteúdos; permitir que os alunos verbalizem por meio da discussão; estimular e reconhecer as contribuições de cada aluno; oferecer situações concretas que mantenham raciocínio em ação; exercitar e estimular o trabalho cooperativo; bem como oferecer material e atividades numa visão integrada aos demais campos do conhecimento humano. 
A seção temática tem, ainda, a dupla pretensão de promover reflexões acerca do trilhar inclusivo e das práticas e programas pedagógicos correlatos a esse processo. Desse modo, diante do paradigma inclusivo, os profissionais e pesquisadores da educação especial e inclusiva unem-se para construírem um ambiente democrático de ensino com todos os subsídios, identificando e atendendo necessidades educativas de cada estudante.

Em suma, os textos trazem experiências educacionais variadas que tratam desde a gestão pública e intersetorialidade na construção de políticas educacionais inclusivas; metodologias de ensino a partir do DUA; ensino diferenciado; construção de escolas criativas; estratégias para o processo de transição escolar e vida adulta; e pesquisas a partir da narrativa de alunos e de bailarinas cegas sobre seus processos educacionais. No contexto de metodologias disciplinares específicas há trabalhos que tratam da identificação de talento musical na escola; participação nas aulas de educação física; aprendizagem da matemática; modelação de histórias e organização do pensamento; desenvolvimento de talentos na educação de jovens e adultos; e propostas de formação de professores com análise de experiência em universidade e em formação continuada a partir do DUA e da comunicação alternativa.

A motivação para a organização dessa coletânea de estudos e experiências em um viés mais voltado para experiências educacionais, teve o sentido de promover contribuições na promoção da autonomia e do direito ao ensino equitativo. Consequentemente, esta seção temática constitui contributo teórico e científico para a contemporaneidade. Os artigos contemplam algumas áreas da educação especial e representam os alunos da educação especial, profissionais da educação e pesquisadores - que têm como objetivo construir um caminho seguro de avanços para a inclusão e não retrocessos.

\section{REFERÊNCIAS}

BRASIL. Ministério da Educação. Secretaria de Educação Especial. Política Nacional de Educação Especial na Perspectiva da Educação Inclusiva. Brasília: MEC/SEESP, 2008.

BRAUN, Patrícia; NUNES, Leila Regina d'Oliveira de Paula. A formação de conceitos em alunos com deficiência intelectual: o caso de Ian. Revista Brasileira de Educaşão Especial, [s. 1.], v. 21, n. 1, p. 75-92, mar. 2015. FapUNIFESP (SciELO). Disponível em http://dx.doi.org/10.1590/s141365382115000100006. Acesso em 7 maio 2020.

BRITO, Jessica de; CAMPOS, Juliane Aparecida de Paula Perez; ROMANATTO, Mauro Carlos. Ensino da matemática a alunos com deficiência intelectual na educação de jovens e adultos. Revista Brasileira de Educação Especial, [s. 1.], v. 20, n. 4, p. 525-540, dez. 2014. FapUNIFESP (SciELO). Disponível em http://dx.doi.org/10.1590/s1413-65382014000400005. Acesso em 27 maio 2020.

CANIATO, Rodolpho. Com ciência na educação: ideário e prática de uma alternativa brasileira para o ensino da ciência. 3. ed. Campinas, São Paulo: Papirus, 1992.

CECHIN, Michelle Brugnera Cruz; COSTA, Adriana Corrêa; DORNELES, Beatriz Vargas. Ensino de fatos aritméticos para escolares com deficiência intelectual. Revista Brasileira de Educação Especial, [s. 1.], v. 19, n. 1, p. 79-92, mar. 2013. FapUNIFESP (SciELO). Disponível em http://dx.doi.org/10.1590/s1413-65382013000100006. Acesso em 27 maio 2020.

COELHO, Cristina Lucia Maia; SODRÉ, Cristiane Zago. Raciocínio lógico, avaliação interativa e ludicidade no contexto da inclusão. Revista Ibero-americana de Estudos em Educação, [s. 1.], v. 14, n. 2, p. 470-484, 1 jan. 2019. Disponível em http://dx.doi.org/10.21723/riaee.v14i2.11674. Acesso em 27 maio 2020. 
ESCOBAL, Giovana; ROSSIT, Rosana Aparecida Salvador; GOYOS, Celso. Aquisição de conceito de número por pessoas com deficiência intelectual. Psicologia em Estudo, Maringá, v. 15, n. 3 , p. 467-475, jul./set. 2010. Disponível em http://dx.doi.org/10.1590/S141373722010000300004. Acesso em 7 maio 2020.

FRANCO, Maria Amélia do Rosário Santoro. Prática pedagógica e docência: um olhar a partir da epistemologia do conceito. Revista Brasileira de Estudos Pedagógicos, [s. 1.], v. 97, n. 247, p. 534-551, dez. 2016. FapUNIFESP (SciELO). Disponível em http://dx.doi.org/10.1590/s21766681/288236353. Acesso em 23 maio 2020.

GLAT, Rosana. Desconstruindo representações sociais: por uma cultura de colaboração para inclusão escolar. Revista Brasileira de Educação Especial, [s. 1.], v. 24 (spe), p. 9-20, 2018. FapUNIFESP (SciELO). Disponível em http://dx.doi.org/10.1590/s1413-65382418000400002. Acesso em 22 maio 2020.

LEONEL, Waléria Henrique dos Santos; LEONARDO, Nilza Sanches Tessaro. Concepções de professores da educação especial (APAEs) sobre a aprendizagem e desenvolvimento do aluno com deficiência intelectual: um estudo a partir da teoria vigotskiana. Revista Brasileira de Educação Especial, [s. 1.], v. 20, n. 4, p. 541-554, dez. 2014. FapUNIFESP (SciELO). Disponível em http://dx.doi.org/10.1590/s1413-65382014000400006. Acesso em 27 maio 2020.

MIRANDA, Amanda Drzewinski de; PINHEIRO, Nilcéia Aparecida Maciel. O ensino da matemática ao deficiente intelectual: projetos de trabalho em uma perspectiva contextualizada e interdisciplinar. Revista Educação Especial, [s. 1.], v. 29, n. 56, p. 695-707, 7 nov. 2016. Universidade Federal de Santa Maria. Disponível em http://dx.doi.org/10.5902/1984686x17805. Acesso em 27 maio 2020.

MORI, Nerli Nonato Ribeiro et al. Jogos e brincadeiras no desenvolvimento da atenção e da memória em alunos com deficiência intelectual. Práxis Educativa, [s. 1.], v. 12, n. 2, p. 551-569, 2017. Universidade Estadual de Ponta Grossa (UEPG). Disponível em http://dx.doi.org/10.5212/praxeduc.v.12i2.0015. Acesso em 22 maio 2020.

NADAL, Beatriz Gomes (org.). Práticas pedagógicas nos anos iniciais: concepções e ações. Ponta Grossa: UEPG, 2007.

OLIVEIRA, Amália Rebouças de Paiva; VAN MUNSTER, Mey de Abreu; GONÇALVES, Adriana Garcia. Desenho Universal para Aprendizagem e Educação Inclusiva: uma revisão sistemática da literatura internacional: uma Revisão Sistemática da Literatura Internacional. Revista Brasileira de Educação Especial, [s. 1.], v. 25, n. 4, p. 675-690, dez. 2019. FapUNIFESP (SciELO). Disponível em http://dx.doi.org/10.1590/s1413-65382519000400009. Acesso em 25 maio 2020.

OMOTE, Sadao. Atitudes sociais em relação à inclusão: recentes avanços em pesquisa. Revista Brasileira de Educação Especial, [s. 1.], v. 24, n. esp., p. 21-32, 2018. FapUNIFESP (SciELO). Disponível em http://dx.doi.org/10.1590/s1413-65382418000400003. Acesso em 20 maio 2020.

PÉREZ, Susana Graciela Pérez Barrera. Mitos e crenças sobre as pessoas com altas habilidades: alguns aspectos que dificultam o seu atendimento. Cadernos de Educação Especial. Santa Maria, n. 22, p. 45-59, 2003.

PIMENTA, Selma Garrido; ANASTASIOU, Léa das Graças Camargo. Docência no Ensino Superior. São Paulo: Cortez, 2002.

PIMENTA, Selma Garrido; GHEDIN, Evandro (org.). Professor reflexivo no Brasil: gênese e crítica de um conceito. 3. ed. São Paulo: Cortez, 2005. 
PLETSCH, Marcia Denise. Repensando a inclusão escolar. diretrizes políticas, práticas curriculares e deficiência intelectual. 2. ed. Rio de Janeiro: NAU, 2014.

ROSSATO, Solange Pereira Marques; LEONARDO, Nilza Sanches Tessaro. A deficiência intelectual na concepção de educadores da Educação Especial: contribuições da psicologia histórico-cultural. Revista Brasileira de Educação Especial, [s. 1.], v. 17, n. 1, p. 71-86, abr. 2011. FapUNIFESP (SciELO). Disponível em http://dx.doi.org/10.1590/s1413-65382011000100006. Acesso em 27 maio 2020.

ROSSIT, Rosana; GOYOS, Celso. Transferência e transformação de funções relacionais de /maior-que/ e /menor-que/ em crianças com deficiência intelectual. Temas em Psicologia, [s. 1.], v. 23, n. 1, p. 137-155, 2015. Associação Brasileira de Psicologia. http://dx.doi.org/10.9788/tp2015.1-10. Acesso em 27 maio 2020.

SANTOS, Roseli Albino dos; MENDONÇA, Suelene Regina Donola; OLIVEIRA, Mercia Cunha. A instituição especializada em tempos de inclusão. Revista Educação Especial, [s. 1.], v. 27, n. 48, p. 41-52, 11 abr. 2014. Universidade Federal de Santa Maria. Disponível em http://dx.doi.org/10.5902/1984686x8755. Acesso em 7 maio 2020.

SEIBERT, Tania Elisa.; GROENWALD, Claudia Lisete Oliveira. Contribuições das neurociências para a educação matemática de uma pessoa com necessidades educativas especiais intelectivas. Revista Educação Especial, [s. 1.], v. 27, n. 48, p. 233-247, 11 abr. 2014. Universidade Federal de Santa Maria. Disponível em http://dx.doi.org/10.5902/1984686x7627. Acesso em 7 maio 2020.

SILVA, Larissa Vendramini da; BEGO, Amadeu Moura. Levantamento Bibliográfico sobre Educação Especial e Ensino de Ciências no Brasil. Revista Brasileira de Educação Especial, [s. 1.], v. 24, n. 3, p. 343-358, set. 2018. FapUNIFESP (SciELO). Disponível em http://dx.doi.org/10.1590/s1413-65382418000300003. Acesso em 22 maio 2020.

SOUZA, Flávia Faissal de; PLETSCH Márcia Denise. A relação entre as diretrizes do Sistema das Nações Unidas (ONU) e as Políticas de Educação Inclusiva no Brasil. In: Revista Ensaio: avaliação de políticas públicas educacionais, v. 25, n. 97, p. 831-853, out./dez. 2017. Disponível em https://doi.org/10.1590/S0104-40362017002500887. Acesso em 15 fev. 2021.

VARGAS, Adriana; PORTILHO, Evelise Maria Labatut. Representações sociais e concepções epistemológicas de aprendizagem de professores da educação especial. Revista Brasileira de Educaşão Especial, [s. 1.], v. 24, n. 3, p. 359-372, set. 2018. FapUNIFESP (SciELO). Disponível em http://dx.doi.org/10.1590/s1413-65382418000300004. Acesso em 20 maio 2020.

ZABALA, Antoni. A prática educativa: como ensinar. Porto Alegre: Artes Médicas, 1998.

Submissão em agosto 2021. Aprovado em agosto 2021.

\section{Informações das autoras}

Carla Luciane Blum Vestena

Universidade Estadual do Centro Oeste 
E-mail:cvestena@unicentro.br

ORCID: https://orcid.org/0000-0002-8655-7840

Link Lattes: http://lattes.cnpq.br/0863582713179217

Carla Maria de Schipper

Centro Universitário Guairacá

E-mail: carlaschipper@gmail.com

ORCID: https://orcid.org/0000-0002-4805-840X

Link Lattes: $\underline{\text { http://lattes.cnpq.br/2425914438206769 }}$

Flavia Faissal de Souza

Universidade do Estado do Rio de Janeiro

E-mail: flaviasouza.ueri@gmail.com

ORCID: https://orcid.org/0000-0003-0225-8358

Link: Lattes: http://lattes.cnpq.br/6545543173378090

Revista Teias v. 22 • n. 66 • jul./set. 2021 • Seção temática Programas e práticas pedagógicas na educação especial e inclusiva 